\title{
Comparison of two spectrometric counting modes for fast analysis of selected radionuclides activity
}

\author{
Magdalena Długosz-Lisiecka ${ }^{1}$
}

Received: 18 November 2015/Published online: 11 January 2016

(c) The Author(s) 2016. This article is published with open access at Springerlink.com

\begin{abstract}
The two counting modes: a normal with a single HPGE detector and second with the additional antiCompton shield of the annular $\mathrm{NaI}(\mathrm{Tl})$ detector have been compared for fast determination of the activity concentration of thorium ${ }^{232} \mathrm{Th}$ in the building materials. The ${ }^{232} \mathrm{Th}$ activity concentration was calculated by measurement of its decay products: ${ }^{212} \mathrm{~Pb},{ }^{212} \mathrm{Bi}$ and ${ }^{208} \mathrm{Tl}$ as well ${ }^{228} \mathrm{Ac}$ content. Although the Compton suppression mode applied in gamma spectrometry systems in general increase sensitivity of the analysis, but in case of $583 \mathrm{keV}$ the most abundant ${ }^{208} \mathrm{Tl} \gamma$-line, the significant reduction of photon counting rate was observed.
\end{abstract}

Keywords Anticoincidence mode - Coincidence photons · Activity equilibrium

\section{Introduction}

Natural thorium radionuclides are always present in environmental samples, e.g. in most rocks and soils, thorium is about three times more abundant than uranium [1]. Soil commonly contains an average of around six parts per million (ppm) of thorium. Mineral waste byproducts and different kinds of building materials can contain high elevated levels of thorium radionuclides as well. According to the EU Directive [2] regarding basic safety standards for protection against the dangers arising from exposure to ionizing radiation, for the purposes of identifying types of

Magdalena Długosz-Lisiecka

mdlugosz@mitr.p.lodz.pl

1 Technical University of Lodz, Institute of Applied Radiation Chemistry, Wróblewskiego 15, 90-924 Łódź, Poland building materials of concern from a radiation protection point of view, the activity concentrations of primordial radionuclides ${ }^{226} \mathrm{Ra},{ }^{232} \mathrm{Th}$ (or its decay product ${ }^{228} \mathrm{Ra}$ ) and ${ }^{40} \mathrm{~K}$ should be determined. The activity concentration index $\mathrm{I}$ is given by the following formula:

$I=\frac{\mathrm{C}_{\mathrm{Ra} 226}}{300}+\frac{\mathrm{C}_{\mathrm{Th} 232}}{200}+\frac{\mathrm{C}_{\mathrm{K} 40}}{3000}$

where $\mathrm{C}_{\mathrm{Ra} 26 \mathrm{6}}, \mathrm{C}_{\mathrm{Th} 232}$ and $\mathrm{C}_{\mathrm{K} 40}$ are the activity concentrations in $\mathrm{Bq} / \mathrm{kg}$ in the building material and the numbers 300, 200 and 3000 are the weighting factors of the corresponding radionuclides, respectively [3-5].

Natural radioactivity in solid environmental samples, including building materials, can be routinely measured by gamma spectrometry system based on various types of detectors. Unfortunately, both long-lived natural thorium radionuclides- ${ }^{232} \mathrm{Th}$ and ${ }^{228} \mathrm{Th}$ - are almost pure $\alpha$ emitters with very low $\gamma$ emission rates: $63.8 \mathrm{keV}-(0.267 \%)$ and $84 \mathrm{keV}-(1.22 \%)$. However, because relatively shorter half-lives of all thorium daughters in the majority of environmental solid samples the radioactive equilibrium for all members of the thorium chain is usually achieved.

If measurement of natural radioactivity in solid environmental samples is provided by a single HPGe or NaI detector, one should take into account the problem known as coincidence summing correction. Usually this problem can be routinely solved for each peak energy line by using special software, e.g. LABSOCS (model S574 LabSOCS Calibration Software, Canberra). Coincidence summing correction is important for isotopes emitting two or more photons in a cascade, e.g. ${ }^{60} \mathrm{Co}[6]$.

Developed anticoincidence (AC) system with a Compton suppression shield has been integrated with a primary HPGe detector and used for measuring low level activity in environmental samples [7, 8]. Due to Compton scattering, 
only part of initial photon energy is absorbed within the active volume of the germanium counter.

A scattered photon can escape from this detector and can be detected at the same time in the surrounding scintillation counter. In a modern active Compton suppression shield with an HPGe as the primary detector, the problem of two or more photon coincidence can occur. This can be a serious problem, because the large shielding $\mathrm{NaI}(\mathrm{Tl})$ and HPGe detectors are working in $\mathrm{AC}$ mode to lower the Compton background [9-11]. Therefore, the two photons coming in cascade from the same nuclide decay may be simultaneously detected by both counters and consequently eliminated, lowering the counting efficiency for that particular $\gamma$ line. Therefore, although the AC system AC mode reduces the natural background of the measurement, it can also reduce signals that occur at the same time interval on both detectors.

In routine measurements, the time range of the $\mathrm{AC}$ mode is equal to $5 \mu \mathrm{s}$, and multi-detector systems are synchronized by the time and energy of the events. To extract coincident events in AC mode, complex electronics are often used to identify accidental coincidences during measurement. As it is evident from Fig. $1 .{ }^{208} \mathrm{Tl}$ radionuclide decays with series of cascade emitting photons with interval times in order of pico or nanoseconds are much shorter than AC gate width interval equal mostly about $5 \mu \mathrm{s}$. Therefore, majority of them can be rejected from the AC spectrum. In single HPGe mode of system such rejection is based only on coincidence summing correction phenomenon, which seems to be negligible for ${ }^{232} \mathrm{Th}$ daughters. Therefore figure of merit (FOM) parameter has been used to characterize the performance of both modes of measurements to determine their relative utility for an application. The objective of the present study is to choose the proper counting mode for ${ }^{232} \mathrm{Th}$ radionuclide progeny based on the FOM criterion.

\section{Materials and methods}

Several types of environmental sample as well as building material (four types of brick, three types of tile, two types of ceramic) were collected from different local ceramic producers in Poland. The samples were crushed to a fine powder then dried at $100{ }^{\circ} \mathrm{C}$ for $24 \mathrm{~h}$ to a constant weight. The geometry of the samples was normalized to disc form with a diameter of $51 \mathrm{~mm}$ and height of $10 \mathrm{~mm}$. The samples were sealed and after one week delay, measured using the analytical $\mathrm{AC}$ mode at 80,000 s.

For measuring natural radioactivity, low-level gamma spectrometry with an active and passive suppression system was used. An HPGe GX3020 counter, with relative efficiency equal to $30 \%$ and 2002CLS (Canberra Inc.) offset preamplifier, was used as the primary detector. The anti-Compton veto system manufactured by SCIONIX (The Netherlands), consisting of a scintillating $\mathrm{NaI}(\mathrm{Tl})$ crystal in aluminum housing with six $3^{\prime}$ photo-multipliertubes to collect the scintillation light and one for the end cap was used as a secondary detector. Both detectors were integrated in a massive low activity lead house and the

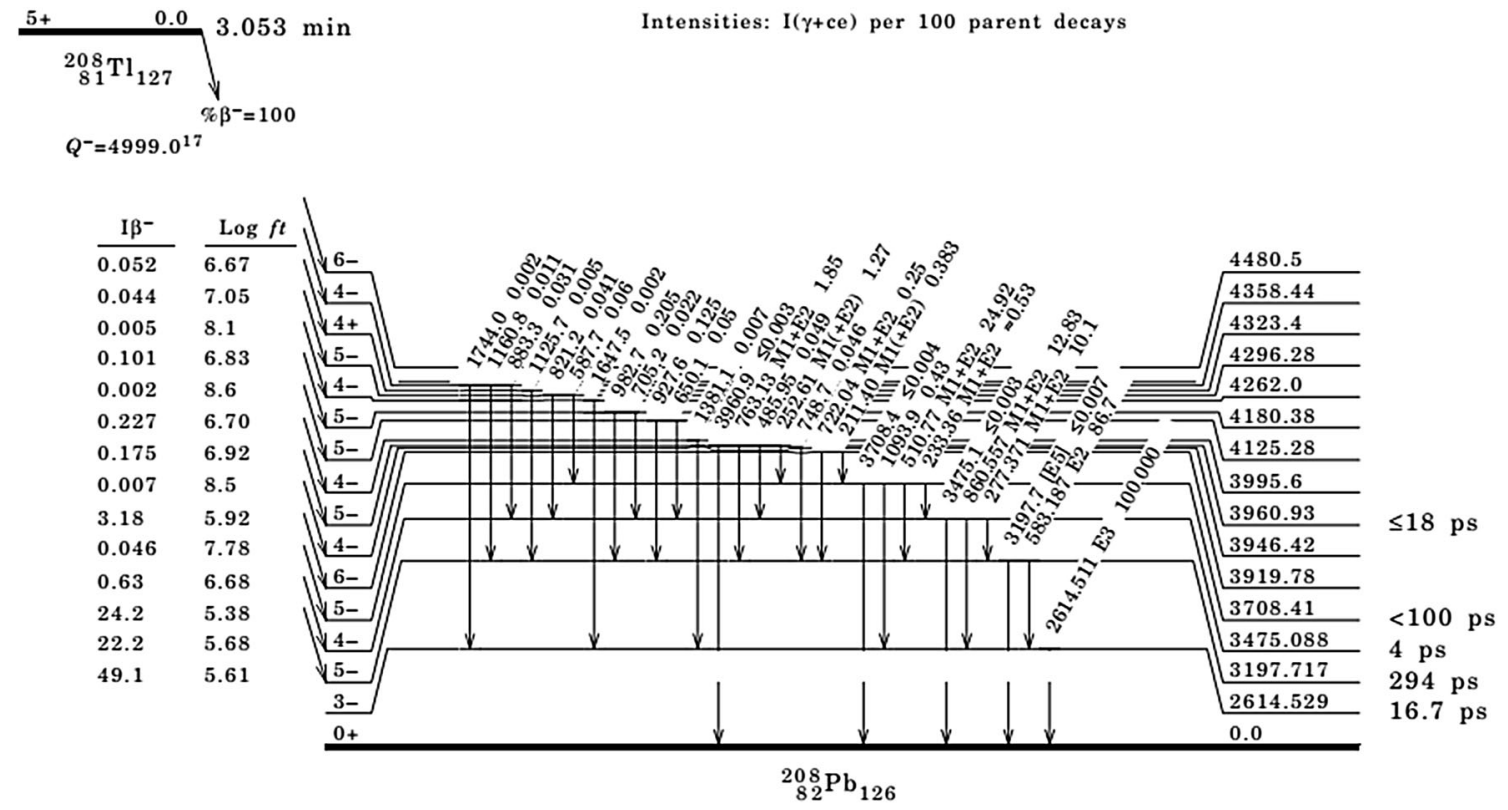

Fig. $1{ }^{208} \mathrm{Tl}$ decay scheme [14] 
interior of the lead house was filled with pure nitrogen gas that evaporating from a Dewar vessel.

The accuracy of the method was checked by measuring under the same geometry as the samples, the two reference materials: IAEA Soil 327 and Soil 375.

\section{Results}

${ }^{232} \mathrm{Th}$ radionuclide can be analyzed by almost any progeny isotope present in its decay chain. In routine $\gamma$ spectrometry measurement, ${ }^{228} \mathrm{Ac}$ and/or ${ }^{212} \mathrm{Bi}$ and/or ${ }^{208} \mathrm{Tl}$ and/or ${ }^{212} \mathrm{~Pb}$ radionuclides are often chosen for this analysis $[4,5,12]$. However, one should remember that in the case of ${ }^{208} \mathrm{Tl}$, only $35.94 \%$ of ${ }^{212} \mathrm{Bi}$ decay leads to this radionuclide, while $100 \%$ of ${ }^{228} \mathrm{Ac}$ or ${ }^{212} \mathrm{~Pb}$ activity are in real secular equilibrium with ${ }^{232} \mathrm{Th}$.

Activity concentration for all chosen radionuclides was calculated on the basis of Eqs. (2) and (3):

$A_{x}=\frac{I_{x}-I_{B K G(x)}}{\varepsilon_{(x)} m}$

$\varepsilon_{(x)}=\varepsilon_{\operatorname{det}(x)} \varepsilon_{\gamma(x)} \varepsilon_{r e d(x)}$

where $A_{x}$-activity concentration of $\mathrm{x}$-isotope $[\mathrm{Bq} / \mathrm{kg}]$, $I_{x}$ - count rate for $x$-isotope in the region of the chosen photon energy line for the sample $[\mathrm{imp} / \mathrm{sec}], I_{B K G(x)}$ count rate for $x$-isotope in the region of the chosen photon energy line for the background [imp/sec], $m$-mass of the sample [kg], $\varepsilon_{(x)}$-absolute efficiency for the chosen photon energy line, $\varepsilon_{\operatorname{det}(x)}$-detection efficiency for the chosen photon energy line estimated on the basis of LABSOCS software, $\varepsilon_{\gamma(x)}$-intensity of the gamma-ray emission, $\varepsilon_{\text {red }(x)}$ - AC reduction factor calculated as ratio of count rate for the chosen photon energy line in $\mathrm{AC}$ mode in relation to the count rate based on a single HPGe measurement.

${ }^{232}$ Th activity concentrations were determined simultaneously by the progenies ${ }^{212} \mathrm{~Pb}(238 \mathrm{keV} \gamma$ energy line), ${ }^{212} \mathrm{Bi}(727 \mathrm{keV}),{ }^{208} \mathrm{Tl}(583$ or $860 \mathrm{keV})$ and ${ }^{228} \mathrm{Ac}$ $(911.1 \mathrm{keV})$. All these radionuclides emit relatively highenergy $\gamma$ photons with energies $>200 \mathrm{keV}$, and therefore self-absorption correction in small thickness samples $(<5 \mathrm{~mm})$ is not necessary.

The AC counting mode can substantially reduce the count rate of the photons emitted in cascade decay, particularly for the most abundant (84.5\%) $583 \mathrm{keV}$ photons of ${ }^{208} \mathrm{Tl}$ (Fig. 1). In that case, practically at the same time (which is shorter than settled AC intervals), photons with energies 277, 727, 511 and $2614 \mathrm{keV}$ are simultaneously emitted [13]. The high-efficiency $\gamma-\gamma$ coincidence events rejected from the AC spectrum can significantly disturb

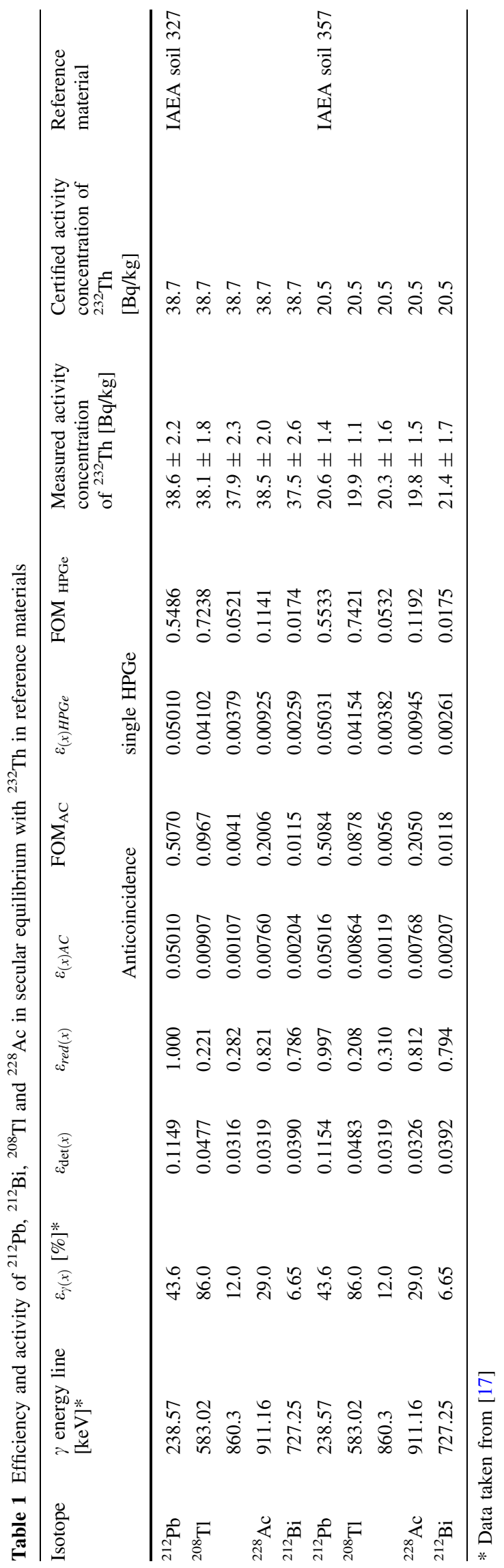


regular spectrometric measurements and as a result reduce the activity concentration of analyzed radionuclides.

In order to choose the proper $\gamma$ line of the examined radionuclides and the best counting mode, the FOM criterion was calculated. The FOM is commonly defined as in Eq. (4):

$\mathrm{FOM}=\frac{\varepsilon_{(x)}^{2}}{I_{B K G(x)}}$

The FOM was calculated for each energy peak of ${ }^{212} \mathrm{~Pb}$, ${ }^{212} \mathrm{Bi},{ }^{208} \mathrm{Tl}$ and ${ }^{228} \mathrm{Ac}$ for normal and $\mathrm{AC}$ counting modes for two reference materials: IAEA soil 327 and IAEA soil $375[15,16]$.

Using AC shield has influence on the count rate of various peak implicit on their detection efficiency $\varepsilon_{(x)}$. The absolute efficiency $\varepsilon_{(x)}$ of the detection system was determined through a series of measurements using two of reference materials obtained from the IAEA; soil 327 and soil 375 (Table 1).
Table 1 shows that the highest absolute efficiency not reduced by the $\mathrm{AC}$ mode was for $238 \mathrm{keV}$ for the ${ }^{212} \mathrm{~Pb}$ isotope. In this counting mode FOM has the highest value equal average 0.5486 . In measurement with using single HPGe detector the highest FOM has ${ }^{208}$ Tl for $583 \mathrm{keV}$ peak energy line [17]. Based on this, it can be concluded that the activity concentration of ${ }^{232} \mathrm{Th}$ can be measured with the highest precision using this line of the ${ }^{208} \mathrm{Tl}$ isotope.

The results of measuring the activity concentration of ${ }^{232} \mathrm{Th}$ in the examined samples, calculated as average activities of its progenies are presented in Table 2.

Simple activity concentration analysis shows no activity equilibrium between each radionuclides-progenies of ${ }^{232} \mathrm{Th}$. Estimation and application of $\varepsilon_{\text {red }}(x)-\mathrm{AC}$ reduction factor in activity analysis of such radionuclides can give correct value. Activity concentration in the brackets are values calculated on the base $\varepsilon_{\text {red }(x)}$ of reference materials taken from Table 1.

Table 2 Measured activity of the ceramic materials in AC mode and with efficiency reduction correction

\begin{tabular}{|c|c|c|c|c|c|c|}
\hline Type of sample & Mass $[\mathrm{g}]$ & $\mathrm{A}_{\mathrm{Pb}-212}[\mathrm{~Bq} / \mathrm{kg}]$ & $\mathrm{A}_{\mathrm{Bi}-212}[\mathrm{~Bq} / \mathrm{kg}]$ & $\mathrm{A}_{\mathrm{Ac}-228}[\mathrm{~Bq} / \mathrm{kg}]$ & $\mathrm{A}_{\mathrm{Tl}-208}[\mathrm{~Bq} / \mathrm{kg}]$ & $\mathrm{A}_{\mathrm{Th}-232}[\mathrm{~Bq} / \mathrm{kg}]$ \\
\hline Chinese plate & 45.6 & $104.2 \pm 6.7$ & $\begin{array}{l}76.3 \pm 3.2 \\
(97.3)\end{array}$ & $\begin{array}{l}79.9 \pm 4.9 \\
(97.7)\end{array}$ & $\begin{array}{l}23.3 \pm 1.8 \\
(105.4)\end{array}$ & 101.1 \\
\hline Italian plate & 29.9 & $41.1 \pm 2.2$ & $\begin{array}{l}33.6 \pm 2.5 \\
(42.8)\end{array}$ & $\begin{array}{l}34.5 \pm 2.6 \\
(42.0)\end{array}$ & $\begin{array}{l}8.55 \pm 0.93 \\
(39.5)\end{array}$ & 41.5 \\
\hline Wall part & 33.9 & $41.5 \pm 2.1$ & $\begin{array}{l}32.6 \pm 2.4 \\
(41.5)\end{array}$ & $\begin{array}{l}36.7 \pm 2.5 \\
(41.7)\end{array}$ & $\begin{array}{l}9.02 \pm 0.84 \\
(40.85)\end{array}$ & 41.4 \\
\hline Polished tile & 41.4 & $42.2 \pm 2.3$ & $\begin{array}{l}34.3 \pm 2.9 \\
(43.7)\end{array}$ & $\begin{array}{l}35.9 \pm 2.8 \\
(43.9)\end{array}$ & $\begin{array}{l}8.87 \pm 0.85 \\
(40.6)\end{array}$ & 42.8 \\
\hline Ceramic plate & 42.6 & $44.5 \pm 2.2$ & $\begin{array}{l}32.3 \pm 2.5 \\
(41.2)\end{array}$ & $\begin{array}{l}34.2 \pm 2.9 \\
(41.8)\end{array}$ & $\begin{array}{l}9.07 \pm 0.75 \\
(41.1)\end{array}$ & 42.1 \\
\hline Chimney block & 30.2 & $32.0 \pm 1.8$ & $\begin{array}{l}25.7 \pm 2.7 \\
(32.8)\end{array}$ & $\begin{array}{l}25.9 \pm 2.2 \\
(31.6)\end{array}$ & $\begin{array}{l}7.23 \pm 0.77 \\
(33.2)\end{array}$ & 32.4 \\
\hline Unbaked brick & 39.0 & $21.5 \pm 1.8$ & $\begin{array}{l}19.9 \pm 1.7 \\
(25.4)\end{array}$ & $\begin{array}{l}18.8 \pm 1.4 \\
(22.9)\end{array}$ & $\begin{array}{l}5.25 \pm 0.52 \\
(23.7)\end{array}$ & 23.4 \\
\hline Chinese cup & 43.7 & $50.2 \pm 3.2$ & $\begin{array}{l}39.2 \pm 2.7 \\
(50.1)\end{array}$ & $\begin{array}{l}43.1 \pm 1.4 \\
(52.5)\end{array}$ & $\begin{array}{l}10.89 \pm 0.81 \\
(49.3)\end{array}$ & 50.5 \\
\hline Ceramic plate (brown) & 30.8 & $39.2 \pm 2.0$ & $\begin{array}{l}33.1 \pm 2.5 \\
(42.2)\end{array}$ & $\begin{array}{l}33.7 \pm 1.6 \\
(41.1)\end{array}$ & $\begin{array}{l}8.97 \pm 0.85 \\
(40.6)\end{array}$ & 40.8 \\
\hline Strzegom granite & 30.5 & $56.7 \pm 5.7$ & $\begin{array}{l}43.4 \pm 3.2 \\
(55.3)\end{array}$ & $\begin{array}{l}44.2 \pm 3.8 \\
(53.9)\end{array}$ & $\begin{array}{l}11.5 \pm 0.9 \\
(52.1)\end{array}$ & 54.5 \\
\hline Vesuvius lava & 30.6 & $42.1 \pm 2.8$ & $\begin{array}{l}33.9 \pm 6.3 \\
(43.1)\end{array}$ & $\begin{array}{l}32.1 \pm 2.2 \\
(39.2)\end{array}$ & $\begin{array}{l}9.09 \pm 1.28 \\
(41.3)\end{array}$ & 41.4 \\
\hline Rock, uranium mineral & 30.4 & $67.7 \pm 4.1$ & $\begin{array}{l}56.0 \pm 6.2 \\
(71.8)\end{array}$ & $\begin{array}{l}56.4 \pm 6.3 \\
(68.8)\end{array}$ & $\begin{array}{l}14.5 \pm 1.6 \\
(65.9)\end{array}$ & 68.6 \\
\hline Soil & 27.9 & $23.4 \pm 1.9$ & $\begin{array}{l}19.0 \pm 3.3 \\
(24.2)\end{array}$ & $\begin{array}{l}18.4 \pm 1.1 \\
(22.4)\end{array}$ & $\begin{array}{l}4.82 \pm 0.76 \\
(21.9)\end{array}$ & 22.9 \\
\hline Chinese ceramic (cup) & 43.7 & $48.6 \pm 3.6$ & $\begin{array}{l}36.9 \pm 3.3 \\
(46.9)\end{array}$ & $\begin{array}{l}39.6 \pm 2.9 \\
(48.3)\end{array}$ & $\begin{array}{l}9.98 \pm 0.74 \\
(45.4)\end{array}$ & 47.3 \\
\hline
\end{tabular}




\section{Conclusions}

The ${ }^{232}$ Th radionuclide was measured in various different solid materials, including building materials and environmental samples. The described procedure makes it possible to quickly determine the activity concentration of ${ }^{232} \mathrm{Th}$ in small solid ( $<50 \mathrm{~g})$ samples. Using AC and single HPGe counting modes made it possible to verify the efficiency of coincidence signals. The FOM criterion was calculated in order to choose the best counting parameters. For the $583 \mathrm{keV}$ line of ${ }^{208} \mathrm{Tl}$ in single HPGe counting mode, the FOM criterion achieved the highest value. The AC mode can lead to a significant reduction of the count rate for ${ }^{208} \mathrm{Tl}$ $(583 \mathrm{keV}),{ }^{212} \mathrm{Bi}(727 \mathrm{keV})$ and ${ }^{228} \mathrm{Ac}(911 \mathrm{keV})$. For ${ }^{208} \mathrm{Tl}$ reduction of counting rate in this mode has been significant. In AC mode average only $21 \%$ of photons with energy $583 \mathrm{keV}$ for ${ }^{208} \mathrm{Tl}$ radionuclide in relation to single HPGe has been identified correctly. Not using external standards and precisely verifications the detection efficiency in AC mode seems to be useless or can lead to significant errors in assays radionuclide activity. Sophisticated electronic AC systems applied for activity concentration analysis of such radionuclides seems to be useless or at best can lead to significant mistakes in routine analysis.

Acknowledgments This research work is supported by The National Science Centre under SONATA Grant No. UMO-2012/07/ D/ST10/02874.

Open Access This article is distributed under the terms of the Creative Commons Attribution 4.0 International License (http://crea tivecommons.org/licenses/by/4.0/), which permits unrestricted use, distribution, and reproduction in any medium, provided you give appropriate credit to the original author(s) and the source, provide a link to the Creative Commons license, and indicate if changes were made.

\section{References}

1. Kok K (2009) Nuclear engineering handbook. CRC Press, Taylor and Francis Group, USA. ISBN 978-1-4200-5390-5
2. COUNCIL DIRECTIVE 2013/59/EURATOM of 5 December 2013, Official Journal of the European Union L 13/1; 17.1.2014

3. Długosz-Lisiecka M, Ziomek M (2015) Direct determination of radionuclides in building materials with self-absorption correction for the 63 and $186 \mathrm{keV} \gamma$-energy lines. J Environ Radioact 150(01):44-48

4. Nuccetelli C, Pontikes Y, Leonardi F, Trevisi R (2015) New perspectives and issues arising from the introduction of (NORM) residues in building materials: a critical assessment on the radiological behavior. Constr Build Mater 82:323-331

5. Trevisi R, Risica S, D'Alessandro M, Paradiso D, Nuccetelli C (2012) Natural radioactivity in building materials in the European Union: a database and an estimate of radiological significance. J Environ Radioact 105:11-20

6. Britton R, Davies AV, Burnett JL, Jackson MJ (2015) A highefficiency HPGe coincidence system for environmental analysis. J Environ Radioact 146:1-5

7. Britton R, Burnett JL, Davies AV, Regan PH (2015) Coincidence corrections for a multi-detector gamma spectrometer. Nucl Instrum Methods Phys Res 769:20-25

8. Britton R, Regan PH, Burnett JL, Davies AV (2014) Next generation detection systems for radioactive material analysis. Nucl Data Sheets 119:410-412

9. Zhang W, Ungar K, Stukel M, Mekarski P (2014) A gammagamma coincidence/anticoincidence spectrometer for low-level cosmogenic ${ }^{22} \mathrm{Na} /{ }^{7} \mathrm{Be}$ activity ratio measurement. J Environ Radioact 130:1-6

10. Semkow TM, Parekh PP, Schwenker CD, Khan AJ, Bari A, Colaresi JF, Tench OK, David G, Guryn W (2002) Low-background gamma spectrometry for environmental radioactivity. Appl Radiat Isot 57:213-223

11. Siversn M, Hofmann M, Mannel T, Feilitzsch F, Oberauer L, Potzel W, Schönert S (2014) Low-level $\gamma$-ray spectrometry at the underground laboratory garching. Appl Radiat Isot 91:49-56

12. Al-Azmi D (2008) Simplified slow anti-coincidence circuit for Compton suppression systems. Appl Radiat Isot 66:1108-1116

13. National Nuclear Data Center, Data Sheet Tl-208. http://www. nndc.bnl.gov/chart/decaysearchdirect.jsp?nuc $=208 \mathrm{TL} \& u n c=$ nds

14. Martin MJ (2007) Nuclear data sheets for $A=208$. Nucl Data Sheets 108:1583-1806

15. http://www.iaea.org/inis/collection/NCLCollectionStore/_Public/ 32/042/32042411.pdf

16. https://nucleus.iaea.org/rpst/Documents/rs_iaea-375.pdf

17. Browne E, Firestone RB, Shirley VS (2004) Table of radioactive Isotopes. Wiley John and Sons, Incorporated. ISBN 978-0471849 094 